\title{
Grandeza y alicismo en la obra de Francisco García Calderón
}

\author{
Por JOSE JIMENEz BORJA
}

El 2 de Julio de 1953 falleció en su residencia de Miraflores, en las inmediaciones de Lima, Francisco García Calderón, concentrado signo de las letras peruanas, figura gloriosa de la generación que aparece con el novecientos que señorea hasta la generación "Colónida" surgida en 1916. Retirado de toda actividad desde hacía ocho años, a raíz de su retorno de Europa, sólo se le vió aparecer en público como disertante una sola vez. Antigua enfermedad nerviosa había hecho crisis en él con motivo de su reclusión por la Alemania hitlerista durante la última guerra, mientras desempeñaba la plenipotencia del Perú en Francia Casjedesconocido porlos jóvenes que rinden tributo a las corrientes literarias más inmediatas, lejana su brillante actuación diplomática, desconectado de la evolucionada saciedad de hoy, este gran señci del pensamiento, de la vida pública y de la aristocracia limeña, tuvo simples exequias, en las que la única nota do grandeza fueron unas hondas y bruñidas palabras de Víctor Andrés Belaúnde en nombre de la Academia Peruana de la Lengua. Había nacido en 1882 en Valparaíso (Chile), en circunstancias aciagas para su país, y mientras su padre, el ilustre jurisconsulto y maestro don Francisco García Calderón, Presidente de la República, se encontraba prisicnero. Hizo estudios de Letras y Derecho que no coronó con el grado académico, en la Universidad de San Marcos y realizó su primer viaje al viejo continente en 1905. Retornó al Perú luego, por breve tiempo, contrajo matrimonio con la distinguida dama limeña Rosa Amalia Lores y regresó a Eurcpa para una estancia de cuarenta años. Allí ejerció distintos cargos diplomáticos: fue Ministro en Bélgica y en Francia y Delegado a la Liga de las Naciones. Por más de diez años 
se apartó por convicciones cívicas del servicio y vivió malesta y ejcmplarmente de su pluma, entre 1920 y 1930. París áué el centro de su fervor intelectual y su residencia favorita. En 1904 publicó en Lima su primer volumen, "De Litteris", con prólogo de José Enrique Rodó, quien saluda en el joven escritor los "anticipados sabores de la madurez" y le vaticina fecundo porvenir crítico.. Brunetiére y Spencer en la Filosofía; Menéndez y Pelayo, Altamira, Núñez de Arrce, Chocano y el mismo Rodó en la literatura, son los temas de estos ensayos en agraz, pero en los cuales hay ya criterio penetrante y equilibrado y sentido armonioso de la prosa. En Europa siguieron: "Hombres e Ideas de nuestro Tiempo", "Profesores de Idealismo", "Ideologías", "Le Perou Contemporain", "Les Democraties Latines de l'Amerique", "La Creación de un Continente", "El Dilema de la Gran Guerra", "El Panamericanismo", "El Wilsonismo", "Europa Inquieta", "El Espíritu de la Nueva Alemania", "La Herencia de Lenin y Otros Artículos", durante cuarenta años laboriosos, sacrificados, tenazmente adheridos al trabjo de meditar y escribir. "La Nación" de Buenos Aires y atros importantes diarios, así como revistas de Europa y América, publicaron durante ese tiempo sus asiduas colaboraciones. Su prestigio fue pronto continental y alcanzó la estimación de la mejor inteligencia española y francesa. Sus libros en francés tuvieron sendas prólogos de Gabriel Séailles y Raymond Poncairé. Su existencia podríamos resumirla diciendo que vivió una vida universal en el Perú y una vida peruana y americana en Europa si la vida puede expresarse mediante las preocupaciones trascendentales que la norman y fecundan.

El pensamiento de García Calderón hay que situarlo dentro del ciclo ideológico que le tocó vivir en el apogeo de su existencia y de su genio. Es sin duda el continuador del idealismo de Rodó, bajo la inspiración luminosa de Ariel, con aquella amplitud de mirajes que llevan al espíritu a las más altas culminaciones metafísicas, éticas y estéticas, con el estímulo de la cultura clásica y cristiana y las corrientes más modernas y audaces para aquel momento de superación del positivismo y mecanicismo anteriores. Ansía una renovación profunda y heroica, religiosa y vidente, del alma americana mediante la sugestión inefable de grandes principios conductores. Semejante idealismo tiene mucho de ingrávido y lírico y hasta de gaseoso, como se ha dicho, pero corresponde $\alpha$ un estado de alma de época, y es por otra parte, lleno de desinterés y de nobleza, auténtica en su sinceridad y en su fe y necesario para el comienzo de toda grandiosa aventura. En García Calderón progresa, además, con el estudio concreto de las rea- 
lidades, hacia un pragmatismo templado o un idealismo práctico, original y sincrética conclusión de su espíritu. Emprende el estudio de su patria como una fuente de material geografía y material sociedad para elevarse a la esfera continental y luego a la universal. Por eso es pertinente el análisis de su primer libro representativo "Le Perou Contemporain", publicado en 1907. Como Taine trata de hacer allí "la anatomía de la historia", descubriendo en cada época las fuerzas directoras $y$ encadenando unas con otras en una estructura severa $y$ fuerte. Describe en primer término el territorio precisando su poder generador sobre los hechos, aquella intima relación entre naturaleza y cultura que constituye la solera nacional; analiza las razas separadas y en la dinámica de sus choques y alianzas; sintetiza el pasado remoto de las civilizaciones indígenas y el inmediato de la colonia y la república; pintcr las costumbres del campo y de las ciudades; y sigue minuciosamente "la evolución de las ideas y los hechos" en el capítulo asi nominado y que es el esencial del libro. Para este efecto parte del estado social durante la dominación española en que la religión es clave de la existencia dando unidad al pesamiento, la política, las costumbres, aunque en contradicción con la pobreza de lo ascético $\mathrm{y}$ el goce de la vida, afirma, en medio de un clima voluptuoso en que florece el amor caballeresco y el conceptismo elegante. El individualismo heroico de la conquista se debilita y desaparece dejando paso a la agilidad imaginativa y la discciación sentimental. Se destruye el equilibrio español "entre la personalidad individual y el Estado. Este queda sólo en el campc; es el único actor. El subconciente de la libertad fermenta como una reacción final a la aplastante maquinaria del Estado español. El ejemplo de la Gran Revolución es el más decisivo; pero ésta no hace el milagro de traspasar su espíritu de orden, de claridad, de unificación. En consecuencia la falta de conciencia en el pensamiento $\mathrm{y}$ en la vida y de energía autónoma, determinaron el egotismo y la anarquía. En estas circustancias el cesarismo reemplazó al antiguo Estado Español. Quedó sin embargo, el resplandor del movimiento libertario como una epónima y misteriosa acción continental, llena de significado y de designios. Los dos grandes nombres que lo concentran, San Martín y Bolívar, oponen diferentes tendencias a la gloriosa epopeya. San Martín se aproxima a Washington y Bolívar a Napoleón. El uno sencillo hasta la timidez, generoso, tradicionalista mitigado, busca la igualdad con detrimento de la libertad; el otro genial, gran visionario dentro de su ambición y su egoísmo, tipo psicológico del criollo, generalizador utópico, busca la libertad con detri- 
mento de la igualdad. El choque que sobreviene entre ellos no es personal: es de dos tendencias contradictorias, dos métodos democráticos que van a prolongarse en el estadio republicano. Hasta 1851, continúa García Calderón, en el Perú impera el cesarismo militar frente al elemento civil indolente y blando. El idealismo de la raza aspira, no obstante, $\alpha$ un ideal más alto en la vida pública y se abre un período de realización jurídicas entre 1851 y 1866. Desde este año hasta 1895 hay una etapa de contrastes y regresiones que no alcanza a superar la brillante administración civil de 1872-76. En 1895 comienza una era económica y positiva. Es la del trabajo, el orden, el entusiasmo y la extensión de la riqueza. Está presidida por una religión nueva, el patriotismo. Ella es la llamada a depurar las esencias nacionales por un vigoroso cauterio sobre males heredados y rebeldes que agobian todavía, en gran parte, nuestro ser colectivo: papel primario de la inteligencia, incertidumbre de la voluntad, personalismo, culto del decorum en el estilo $\mathrm{y}$ en la yida, plutocracia excesiva y deprimente. La severidad del diagnóstico no empaña la brillantez del optmismo final con la.frase d'annunzziana: hay todavía muchas auroras que no han nacido.

Este libro es sólo la larvada meditación de "Les Democraties Latines de l'Amerique", escrito en 1911, como un homenaje al primer centenario de la emancipación continental y que está traducido al inglés y al alemán. Allí, con igual sentido de las cosas y las hechos, lejos de todo desbórderománfico ólexaltación retórica, con franqueza viril y descarnada para los defectos de todos y de cada uno, partiendo de una verdadera ponderación clínica, analiza la formación de las sociedades americanas; las luchas por la independencia; la anarquía militar y el período industrial; el caudillismo en .Venzuela, el Perú, Bolivia, el Uruguay y la Argentina; el principio de autoridad en Méjico, Chile, el Brasil y el Paraguay; las formas de la anarquía política en Colombia, el Ecuador, Haití y Santo Domingo; la evolución intelectual mediante la ideclogía política de conservadores y liberales; la influencia de las ideas inglesas; la literatura y la filosofía en las nuevas democracias; el espíritu latino que anima éstas y los peligros de la América del Norte, Alemania y Japón; y finalmente, los problemas abiertos a la incógnita del porvenir : la unidad o la dispersión; las razas y sus luchas y alianzas; la estabilidad política y las soluciones jurídicas; los interrogantes financieros y comerciales en torno a la correspondiente autonomía económica en un laboratorio de hombres libres, para concluir, siempre con optimismo: "Si en una Europa domi- 
nada por alemanes o eslavos, los pueblos del Mediterráneo son obligados a retroceder en un triste éxodo hacia el mar azul poblado de islas griegas y de símbolos tan antiguos como el mundo, probablemente el mito legendario se realizará de nuevo y la antorcha que contiene el ideal de la civilización latina pasará de París a Buenos Aires - Río de Janeiro, como pasó de Roma a París en la época moderna, como pasó de Grecia a Roma en la épaca clásica. La América hoy día desierta y dividida, salvará la cultura de Francia y de Italia, la herencia de la Revolución y del Renacimiento y habrá así justificado hasta su fin la audacia de Cristóbal Colón". La clarividencia de este libro, su acervo científico, positiva y cuidadosamente sistemado, su vibración mesiánica, hacen que olvidemos muchas limitaciones o que le rindamos tributo a pesar de las discrepancias. La vehemencia por ver organizados estos países lo inclina a la salud que cree descubrir en las fuerzas tradicionales: "El idealismo liberal vence al buen sentido conservador. Lastarria seduce a la juventud impetuosa más que Bello y Alberdi; Guizot tiene pocos lectores; Lamartine y Benjamin Constant son papulares. Liberalismo, radicalismo, jacobinismo: he aquí las diferentes máscaras de la anarquía sudamericana" Hay también la ausencia de lo que ahora es una lacerante emoción y una centella mística respecto del problema social. Al tratar lo peruano asimismo reduce lo complejo del país a la costa marítima cuando considera decisivo sobre el carácter patrio el clima sedante $Y$ voluptuoso de esta región. En lo peruanó ygen lo ámericanonhay Sexcesiva reverencia $a$ lo europeo transculturado y falta de penetración para conectarse $a$ los mantos subyacentes de nuestra riqueza original. Esta falta de arrebato intuitivo para descubrir un mensaje milenario que ahora se vierte en fuego áurec sobre el pensamiento, la poesía y el arte de las nuevas generaciones es sin duda su defecto mayor.

"La Creación de un Continente", escrito en 1912, es un libro profético, estremecido en la fe de nuestro gran destino; armoniosamente lírico sin dejar de ser metódico, puntual y objetivo; cáustico en la etiología de nuestros males; poderoso en las síntesis de la evolución histórica; rico en observaciones del medio hasta constituir un breviario de sociología hispanoamericana. En tres grandes sectores desarrolla los temas de la unificación, el americanismo y la autonomía. En el primer sector plantea la independencia como fenómeno de disgregación en que tumultuosomente, sobre los restos de los virreynatos, capitanías y audiencias, se erigen apartadas repúblicas. Pero del fondo de la infecunda dispersión surge el anhelo de unidad. Rememora las asambleas 
que descie el Congreso de Panamá han pretendicio restablecerla. Frente al dilema de paniberismo y panamericanismo asume una actitud cléptica : la tradición ibérica es necesaria al continente, por su lengua Y su cultura, pero no el restablecimiento de la hegemonía española. España deberá tener sólo un sitio de honor, dentro de una liga fraternal de pueblos libres. De otro lado el panamericanismo es una realidad geográfica. La vecindad de los Estados Unidos impone a HispanoArnérica relaciones económicas que pueden ser provechosas para su progreso. También le es provechosa la soiiciaridad de la Doctrina Monroe que le garantiza la inclependencia contra las ambiciones de otras continentes y la tutela jurídica que representa la mediación norteamericana en los conflictos internos, evitando las guerras fraticidas. Pero Hispano-América debe cuidarse de la expansión yanqui más que por los tratados y literatura diplomática por la cohesión de sus fuerzas, por el incremento de su población, el desarrollo de su riqueza y el esclarecimiento de su cultura. El vigoroso despliegue de su perscnalidad histórica será su mejor garantía. Esta personalidad ya se va plasmando con el aporte universal : "de aquel abuelo tiene el vástago la viriliclad; de otro progenitor el fervor artístico; el medio le dará el gusto de la libertad; el libro francés, claridad y sutileza; la lectura dé los clásicos españoles, solemne elocuencia". Lo americano impondrá el sello definitivo: "ni latinos ni iberos, pero sí americanos". "Será una nueva España, una Francia de Ultramar, una colonia latina? Es sólo América, novedad en la "flora y en la tierra, gestacion" de hombres nuevos, lenta fundación de una civilización liberal a la luz de nuevas estrellas. Es el milagro americano que asombrará al mundo como a la admiración erudita de Renán el inexplicable milagro griego". El americanismo sajón y el latino vivirán así en sus propias esferas la respectiva grandeza. Esta ya se presiente para el continente sur. Del fondo convulso de sus propios defectos, se elevan positivas virtudes. Nos domina un disolvente individualismo que conspira contra todo esfuerzo de unidad, contra todo orden y toda ley. La anarquía política es el corolario. Nuestro idealismo es verbal y se satisface con la vaguedad de los principios humanitarios sin llegar a plasmarlos: arbitraje, democracia, libertad. La política es declamatoria y estéril y degenera en luchas personales. La igualdad se confunde con la envidia niveladora y la organización con la tiranía. El culto desmesurado del valor -herencia del quijotismo heroico- engendra la figura del caudillo. Antes que la virtud cívica vale el coraje personal, la audacia romántica : la política se convierte en asalto. Pero no olvidemos que en medio de ese cuadro 
sombrío e inestable existe la familia, con permanencia, lazos vigorosos, espíritu de sacrificio, muy distinta a la familia de los Estados Unidos; que los iberoamericanos se distinguen por brillantes cualidades intelectuales $\mathrm{y}$ que cuando dejan de lado la imitación comienzan a producir valiosa y peregrinamente; que a pesar de todos los contrastes avanzan la ordenación jurídica y democrática, la libertad de pensamiento y la tolerancia religiosa; y que en el orden material se incrementan las ciudades $\mathrm{y}$ adelantan las industrias. El nacionalismo sudamericano, a veces arbitrario y que ha degenerado en guerras de conquista, principia asimismo a elevarse a un nivel solidario, a conciliarse con el americanismo. Es ejemplar para García Calderón, en este sentido, e! nacionalismo peruano, puramente defensivo y constructivo. La imperial tradición de los incas y el esplendor de la colonia no han servido a José de la Riva Agüero, su principal exégeta, sino para despertar el anhelo de la restauración interna, lejos de toda ambición de hostilidad - hegemonía. Así también lo ha hecho con el pasado argentino, en obra paralela, Ricardo Rojas. Ese ponderado nacionalismo es útil y fecundo porque detiene el avance del cosmopolitismo foráneo con la amenaza de disolución que traen las olas inmigratorias. Por otra parte, en el crisol nacional, son necesarios los aportes de sangre nueva y las inyecciones de capital financiero. Pero deberán ser activos los agentes de asimilación, principalmente una escuela de gran poder plástico, el culto del pasado legendario elfidioma unificador $Y$ el desarrollo industrial planificado de grandes qlearices.li Se abriró de esta manera el camino hacia la autonomia. Esta deberá emanciparnos totalmente del ciclo de la imitación de ideas y modas, códigos y artes y del ciclo de la dependencia económica en que el oro extranjero domina las finanzas. Para ello necesitamos regenerar todas las fuerzas de que disponemas y rectificar los errores en que hemos caído por inercia centenaria. En ese empeño deberemos principiar por depurar la atmósfera moral en que nos movemos. La religión tradicional puede ser una base apropiada para ello. A pesar de todos su defectos, es todavía instrumento de la unidad nacional; enseña respeto a las jerarquías, difundiendo el orden necesario; predica una moral noble; abre una esperanza y funde a las castas sociales. Frente al industrialismo progresivo puede desarrollar una acción moderadora. Pero es necesario un franco renacimiento de la fe antigua. Nuestro catolicismo ha decaído, se ha burocratizado. Las vocaciones se producen unicamente entre las clases inferiores. Sin robustez creadora ni sentido trágico del deber es religión tímida, sensual y linfática, credo elegante, aristocrático, insti- 
tución del Estado y fórmula necesaria para los grandes actos de la vida civil. A un renacimiento vigoroso del catolicismo deberú seguir un status sagaz de las relaciones con el poder público: ni Iglesia priviligiada ni separada del Estado. La libertad de conciencia y de cultos son artículos necesarios a las Constituciones americanas para evitar la intolerancia que detendría la inmigración y el desarrollo económico. Si esto produce algunas luchas, ellas son preferibles a la plebeya quietud de las almas indiferentes. La Iglesia se volverá activa y conquistadora. El protestantismo será siempre vencido en este suelo, a pesar de Juárez. Es religión abstracta y triste que no se aviene con la agudeza imaginativa y sensorial del trópico. Tampoco tendrá éxilo la moral filosófica del deber que predican los discípulos de Ruskin o la religión humanitaria de Augusto Comte. "El renacimiento religioso únicamente podrá realizarse dentro del catolicismo, religión tradicional, matriz de ideas y costumbres, imponente presión a la que no escapan ni el indio servil ni el español hidalgo", concluye García Calderón. Este idealista que ha sido tildado de irreal y lírico, propugna una educación práctica para Hispana-América que contribuya al desarrollo inclustrial de estos países. "En pueblos que luchan con la miseria y.el desierto debe extenderse la instrucción utilitaria. Necesitan de una élite directora y de multitudes ávidas de independencia y de riqueza. Tienen ya, como los viejos países de Europa bachilleres proletarios y abogados y médicos parásitos. Crece la turba profesional sin fortuna y los presupuestos no alcanzan paraealimentallai Clos hijos de mercaderes e indusiriales ambicionan también el doctorado". "Herederos de la arrogancia española, son todavía hostiles los sudamericanos a la industria y el comercio. La enseñanza debe condenar enervantes prejuicios". Pero el espíritu utilitario no debe constituir un sistema en sí. El espíritu utilitario debe ser sólo parte de una constelación moral en que rijan los ideales superiores, agrega muy oportunamente. Sin ellos se convierte, por el contrario, en fuerza pertubadora y es más vicioso y voraz que la burocracia. Y la educación popular hay que completarla, con el mismo interés, con la educación de las clases dirigentes. García Calderón, en realidad, sintetiza en este admirable capítulo las ideas de Villarán y de Déustua. El uno puso énfasis en la educación popular: el otro en la educación superior. Si leemos bien sus fundamentales ensayos, ninguno negó lo contrario. Para Villarán la educación superior mantenía su importancia. Para Déustua la formación de una aristocracia del talento y del deber, lejos del prejuicio de casta, no excluía la educación popular. En uno y otro caso, lo demás se daba por aña- 
didura. García Calderón, aunque condena el profesionalismo parásito, como Villarán, y propicia una educación popular de sentido pragmático, profesa como Déustua el principio de una clase directora esmeradamente educada y consciente, capaz de imprimir rumbos ideales y superar la estrechez de la mentalidad plutocrática. "No se forman modernas democracias, precisa, bajo la acción de negociantes y banqueros. Una aristocracia tutelar preside el desarrollo nacional. La educación de esa élite, es pues, tan necesaria como la educación de la multitud, principalmente en América donde no existen tradiciones políticas ni cuadros inviolados. La formación de esa élite es, pues, tan necesaria como la educación de la multitud". La transformación social americana es acaso el tema que desarrolla con mayor criginalidad. América, en este campo, no copia a los pueblos feudales de Europa, a las monarquías despóticas de Asia, a los reinos constitucionales o a las colonias sumisas. Las clases sociales de la colonia subsisten después de la independencia, pero desorganizadas y en extravagante confusión. Se suprime hacia 1850 el tributo del indio y la esclavitud del negro. Doctrinas igualitarias propician la mezcla de todas las razas. La aristocracia carece de privilegios y está abierta a toda clase de irrupciones. El dinero es la única valla que separa a los hombres. Surgen las grandes ciudades que democratizan disminuyendo la importancia de cada individuo. Además del postulado de Alberdi "gobernar es poblar" podemos decir : "poblar es democratizar". L Los inmigrantes ascienden rapidamente al primer plano socialin Süsi hijos sonsterratenientes, banqueros, ministros. Mas esta libertad que sólo se detiene ante la fuerza de la finanza ha engendrado un grupo capitalista de fuerza decisiva en los destinos patrios, pero que no tiene lustre ni tradiciones ni generosidad aristocráticas. Casta ambiciosa de monopolios, plutocracia ávida, carece del sentido social que tiene la clase adinerada de los Estados Unidos. Las millonarios hispanoamericanos no protegen las aries ni dotan las universidades y colegios ni premian el esfuerzo y la virtud devolviendo de ese modo algo de lo que ganan facilmente con el admirable desarrollo de la tierra, el concurso del trabajo y el proteccionismo fiscal. "Es limitada y mezquina su ambición. Quieren el poder por el poder, presiden orgullosamente la vida monótona de las ciudades provinciales. Semejantes plutocracias que nada crean en el país son peligrosas". Es imperioso que surja para equilibrarlas una clase media educada, económica, independiente, sin el egoísmo de las clases ricas ni la violencia de los demagogos. Una reforma agraria moderada es también deseable. El desarrollo democrático impone la división legal 
y ordenada de los latifundios. "Multiplicar las pequeñas propiedades, aumentar el número de los poseedores del suelo, tal parece el ideal agrario de la política americana". El instrumento de la transformación, si es que ésta se produce, no será el socialismo, imitación importada tan servil y ajena a la realidad de América como lo fué el federalismo, agente de grandes errores y contrastes, ni lo será tampoco el anarquismo que es un crimen social. Ese instrumento será sin duda el Tercer Estado ambicioso en lucha con la oligarquía, corriente democrática, nacionalista y liberal, que encauce las aspiraciones de vastos sectores de la producción y el trabajo. Toda evolución social supone una evolución económica paralela. Los pueblos americanos viven en saltante inferioridad económica. Carecen de reservas nacionales; todo lo esperan del oro extranjero. La formación del capital nacional es la base de su segura libertad. Deben desarrollar a plenitud su riqueza agrícola e instaurar la edad fabril, orgullosa y expansiva. "En el porvenir americano será ineficaz el esfuerzo que olvide la primacía de los intereses económicos y crea reformar vicios hereditarios con elocuentes cátedras - leyes abigarradas. Sin el tosco apoyo de Calibán, sin el fuerte aliento de la tierra feraz, se fatigarán los innovadores en estériles himnos al ideal. Un vengador materialismo destruirá, en países imperfectos, su generosa utopía". Donde más se necesita cancelar la etapa de las imitaciones es en la estrūctura políticāa Aqui la Ámérica española se ha entregado al vértigo de las creaciones artificiosas. Parlamentos, federación a la manera horteamericana, presidencia "de cuatrienios, apresurada importación de ideas e instituciones, contrastaron con la tierra semibárbara, inestable para sostener sobre improvisados puntales coronamiento de capiteles jónicos. La consecuencia ha sido la confusión caótica, la discordia fratricida y como remedio, la aparición de presidentes que, aún dentro de los límites constitucionales, resultan autócratas. "El hombre-conquistador, déspota o caudillo, es personaje representativo en el desarrollo americano. A su exaltación contribuyen todas las fuerzas sociales". A pesar de sus poderes, los Virreyes tenían el contrapeso de los Cabildos; pero la influencia de éstos ha disminuído o desaparecido. "Más felices que las autoridades españolas, gobiernan los presidentes sin escuchar las protestas de esos cuerpos altivos y la centralización absoluta llega a ser el término de la evolución política". Las asambleas parasitarias, declamadoras y bizantinas deben ser reemplazadas por parlamentos del tipo inglés en que prime la voz de las profesiones y de las clases productoras. "Sin renuciar a la influencia de las mayorías, conviene robustecer el aspecto económi- 
co de los parlamentos y conceder parcial representación a las instituciones existentes, clero, universidades, comercio, agricultura, industrias". Debe irse también a la disolución del actual federalismo, obra funesta del plagio político. "Una política sagaz seguiría dos direcciones complementarias : dentro de cada pueblo, la centralización; en el continente, vínculos que preparen la federación. Repúblicas sólidamente constituídas servirían así de base a la imponente congregación de pueblos soñada por Bolívar, equivalente meridional de la robusta creación sajona. Una progresiva coordinación de esfuerzos creará la unión moral, intelectual y acaso política : primero la restauración del municipio autónomo, después la unidad nacional contra la antigua discordia; y finalmente la amistad política de vigorosas unidades, la gloriosa creación de un continente". El tema de la originalidad intelectual corona este conjunto de revisiones sobre todos las aspectos de la cultura hispanoamericana. La Europa meternal también presta a América sus gastadas imágenes de literatura y de arte y hay poetas versallescos y ojivas góticas. Clásicos y románticos buscan su inspiración en España y en Francia. En cambio el romanticismo francés con Bernardina de Saint-Pierre y Chateaubriaud extrajo de las florestas de América el sentido grandioso y melancólico del paisaje. El individualismo español fue contrario al delirio panteísta. Bello canta el trópico, pero no sobrepasa a Virgilio. Su arte descriptivo no llega a la impresión total, solemne, abrumadora de la naturaleza CamericanaS Esa impresión comienza a realizarse "Gon da intensidad pictórica Yol dinamismo vertiginoso de Heredia. Lo siguen Echevarría y Mármol en El Plata; Pesado y Rodríguez Galván en México; Gonzalves Díaz en el Brasil; y los poetas finişeculares Zorrilla de San Martín, Díaz Mirón, Chocano. En éste último está hondamente acusada la ambición continental. Sus descripciones son audaces y palpitantes. Ninguno lo supera "cuando da $\alpha$ lo inanimado una vida extraña y magnífica". En la novela han sido más raros los intentos análogos. La tristeza del indígena vencido fue revelada por el romántico brasilero José de Alencar. Obligado en la Argentina; Batres Jáuregui en Guatemala; González Obregón en México, Miguel Luis Amunátegui en Chile, evocan cuadros de la conquista y la colonia en el género de las tradiciones creadas por don Ricardo Palma. Nadie sobrepasa al genio del maestro. Nadie iguala la gracia y la belleza de sus narraciones, archivo amable de América. Mas al fundar la tradición Palma ensancha y enriquece una vena literaria genuinamente nuestra que es el criollismo. "Mientras que el americanismo significa evocación de indígenas costumbres, de razas vencidas 
- descripción de la naturaleza tropical, el criollismo es el amor a la vida regional, a los usos del vástago de españales crecido y educado en las ciudacies adormecidas. Gracia, suave escepticismo, agudeza en la crítica, ingenio, brillante indisciplina, constituyen los rasgos del criollismo que revelan vestidos y refranes, comidas y bailes. Existe ya una literatura criolla principalmente en la Argentina y Venezuela, aunque en ella abunden improvisacicnes; el teatro y la novela aspiran a fijar, antes que los destruya el cosmopolitismo invasor, los caracteres de la vida castiza". Las canteras para el arte futuro están intactas. Las ofrecen la peculiar geografía, pródiga y suntuosa; una historia llena de conflictos dramáticos, principiando por el conflicto de las culturas. La majestuosa edad colonial abre una espléndida variedad de temas con su ingenua sapiencia y su mezcla de ambientes toledanos, florentinos y versallescos. Walter Scott, Ânatole France y Barbey D'Aurevilly podrían haberla incorporado a sus creaciones. La misma informe y plebeya edad republicana encierra asimismo elementos de primer crden para la novelística. Hay en ella abundancia de personajes románticos de individualidad exacerbada o tipos heroicos, al estilo de Carlyle. Una literatura de contrastes puede surgir del chcque inevitable de inmigrantes y nativos; $y$ una literatura dolorosa se vislumbra en la tragedia del indio explotado, a la manera de Gorki. La vida tumultuosa de los bosques, la lucha por el caucho y la mujer, pueden motivar una literatura realista casi bravía junto a otra compleja y elegante que nos presente gel laberinto psicológico de las ciudades. La obra de América en ciencias sociales presenta, nás que estas esperanzas, originalidades positivas. Sarmiento y Alberdi aportan soluciones adecuadas a los problemas del continente. Juristas y codificadores han hecho valiosa obra de adaptación. Admirables lingüístas como don Rufino José Cuervo y don Andrés Bello han cumplido una tarea condigna de los más grandes filólogos europeos. La autonomía ha abierto, pues, a pesar de todo, su camina en el reino luminoso del espíritu y una exaltación se avecina en nuestra voz para sumarla a la exaltación de la verdad y la belleza univesarles. Porque quizás, América, y este el colofón del libro, "está destinada desde el origen de los tiempos a que en sus amplias mesetas nazca, hija del Sol, como en la leyenda de los incas imperiales, señor de las cumbres orgullosas y de los ríos tutelares, avasallador y solitario, el Superhombre". No olvidemos para juzgar este vasto y rico ensayo que fue escrito hace más de cuarenta años, antes de las dos guerras mundiales, y que era imposible entonces adivinar acontecimientos que después se han sucedido con 
rapidez y violencia abrumadoras en la historia contemporánea imponiendo nuevos pensamientos, nuevas corrientes y nuevas estimativas a todas las cosas. Sin esta consideración parecerán candorosos algunos de sus juicios, dulcemente confiadas muchas de sus esperanzas e ineficaces gran número de sus remedios. Los sacudimientos estructurales de las últimos años nos han conducido a debilitar nuestra fe en las soluciones de transacción, matizadas y diplomáticas. Con todo, queda para hoy y quedará para siempre, aparte de la visión generosa y la esplendidez del estilo, un sistema de observaciones hondas sobre la realidad americana, caladuras raigales, seccionamientos sorpresivos; una serie de poderosas reducciones de historia y de cultura en símbolos constelados, fúlgidos y quietos; y a pesar de todas las dificultades para presagiar el futuro, un gran conjunto de hechos cumplidos, de' procesos entrevistos y más tarde desenvueltos y culminados. Libro clásico que podemos destacar a la admiración de las nuevas generaciones, "La Creación de un Continente" es en nuestra literatura un ejemplo de aticismo, templete de jónica elegancia sobre la pradera destinada al pensamiento augusto, de mármol griego veteado de indianidad, equilibradamente lírico y grave.

Un capítulo imponente de la obra de Francisco García Calderón eslá constituído por su cátedra europea : es casi medic siglo de recepción, comentario y divulgación de ideas, desda su sede de París, con destino a América Latina y España. Son ensayos cortos, generalmente, o artículos para diarios y revisfors, en que su inteligencia como fina antena percibe con anticipación las ccrrientes que se avecinan, los hombres que descorren horizontes, los libros y los hechos germinales. En su colección forma distintos volúmenes, ya mencionados, entre los que el más representativo es "Profesores de Idealismc". Allí encontramos el panorama completo del pensamiento europeo hacia 1909. Están anunciados libros de Bergson y de Boutroux, entonces todavía en preparación, por confidencia de ambos sus ilustres amigos, libros que después fueron decisivos y famosos en la Filosofía Contemporánea. La metafísica de Bergson está sintetizada y revelada sugestivamente lo mismo que la final' inquietud religiosa de Boutroux. Hallamos asimismo una equilibrada revisión de Taine, en circunstancias en que la crítica histórica y la aparición de nuevos. métodos casi reducía a polvo su gigantesca figura. García Calderón, 'a pesar de su ferviente simpatía, ccepta todo lo que es incontrastable; pero destaca con entusiasmo lo que resta incólume de uno de sus más amados paradigmas : la síntesis de épocas, el color prodigioso, la poesía profunda, la sinceridad y la 
nobleza de la vida. Nos salen al encuentro la oratorio socialista do Jaurés, el pragmatismo de William James, el Congreso Internacional do Filosofía de Heidelberg y el Congreso Socialista de Stuttgart, el toatro intenso de Bernstein y la poesía exquisita de Francois Coppée. No escapan Ferrero, Fogazzaro, Hugel, Croce, Fovillée, los españoles Maeztu y Sorolla. Hay impresiones de ciudades - Berlín, Nueva York - y de ideologías que se precipitan al centro huracanado de la crisis actual : nacionalismo, militarismo, materialismo, lucha de clases, marxismo. La exposición es amena y sonriente, la captación de un poderoso sincretismo, el trazo certero, pulcramente decorado, el escolio sagaz, traspasado de luminoso y compartido razonamiento. Frente a todos los problemas, en el vórtice de las pasiones, entre las cumbres y los abis. mos, escoge invariablemente una posición de medida, eclepticismo y tolerancia. Es ajeno a las scluciones excluyentes de extremos polares. Como su maestro Renán, hubiera preferido el purgatorio al cielo y al infierno, porque éstos son las reinos de la infinita homogeneidad mientras aquel es una mezcla discreta - el sufrimiento intenso pero también la intensa esperanza. Tampoco se encerró nunca dentro de sistemas conclusos, aquellos mundos relucientes y perfectos que ofrecen fórmulas hechas para resolver todas las cuestiones y responder a todos los interrogantes. Pcdríamos decir que es un conservador progresista porque reconoce valores permanentes $y$ defiende principios rectores al mismo tiempo que busca la renovación, el cambio que supere caducas estructuras y viejos errores; pero esa posición és sólo una tendencia flexible y amplia, morigerada por el relativismo, la ironía y la experiencia escéptica.

El estilo de García Calderón cae dentro de los límites de la prosa modernista y es una de sus realizaciones más brillantes y selectas. Rubén Darío escribió sobre García Calderón : "deja el vergel de los lirios y los mirtcs y los laureles para inclinarse al pozo de donde se espera ver salir el blanco cuerpo de la verdad". Y añade que puesta su obra ideológica en un platillo de la balanza psíquica "habría que poner en el platillo opuesto un buen número de toneladas de perlas y de rosas". Es por lo tanto una obra de pensador grave, con hondura filosófica, con vigor y consagración benedictina para el análisis, como el mismo Rubén Darío lo proclama, pero que asciende hasta esta alta esfera desde un carmen apolíneo. Ese carmen es el de la estética modernista. En la forma, le es absolutamente fiel. Hay una musicalidad señorial en su período aunque no se trata de un poema. Son ideas, pero van enlazadas dentro de un largo que corresponde a una lejana, 
dispersa sinfonía. "Sinfonías de ideas" dijeron los modernistas, con reverencia unciosa, de los mensajes de Rodó. No hay nada, por. eso, que nos recuerde a trompetería asordadora; todo nos evoca, más bien, una vaga orquestación de óboes y flautas. Las imágenes visuales so corresponden con las sonoras. Las impresiones que parecen recoger nuestras retinas, en los horizontes tamizados, son de mármoles radiantes. Un paganismo esplendoroso levanta sus bizarrías en el crepúsculo de otoño. La oración, lejos de la pesadez clásica y de la catarata romántica, discurre ágilmente, con gracia, novedad y frescura. Es intencionalmente sobria, pero de pronto la sobresalta una vibración plateresca, un eco de metales finos, un resplandor de piedras preciosas. Su erudición resulta así, al mismo tiempo, un ánfora cincelada : una erudición de filósofo platónico que no puede prescindir de las palabras como elementos divinos, litúrgicos y mágicos. Porque para Platón, según el texto del Cratilo, las palabras constituyen el arte supremo de los dioses : ellos las han creado y se encargan, cada cierto tiempo, do devolverles su sentido verdadero y su belleza bastardeada en boca de los hombres. 